\title{
POR UMA EDUCAÇÃO INFANTIL FEMINISTA: PEDAGOGIA, POLÍTICA E POÉTICAS DA RESISTÊNCIA*
}

Adriana Alves Silva

\section{Primeiro movimento}

\section{Laços de família: infância e melancolia}

Parafraseando Clarice Lispector, colocar-se em movimento: no instante-já. E continuando com ela que sempre é uma tentação, para o despertar,

A raiva me tem salvo a vida. Sem ela o que seria de mim? Como suportaria eu manchete que saiu um dia no jornal dizendo que cem crianças morrem no Brasil diariamente de fome? A raiva é minha revolta mais profunda de ser gente? Ser gente me cansa. E tenho raiva de sentir tanto amor. Há dias que vivo de raiva de viver. Porque a raiva me envivece toda: nunca me senti tão aler$\mathrm{ta}^{1}$.

A pesquisa de Doutorado, que resultou na tese $A$ estética da infância: poéticas e culturas infantis (SILVA, FE/Unicamp, 2014), foi um processo de pesquisa e criação, articulando Artes e Ciências Humanas. A tese está dividida em dois momentos: o primeiro, que situa a pesquisa a partir da busca de um entrelaçamento de tempos distintos e complementares de minha trajetória pessoal e acadêmica, no intuito de construir uma linguagem autoral que me permitia criar uma exposição, na qual a forma e o conteúdo do meu tema, a estética da infância

\footnotetext{
*DOI - 10.29388/978-65-86678-02-4-0-f.203-220

${ }^{1}$ Fragmento da crônica "Fartura e carência", publicada em 14.09.68. In: A descoberta do mundo, p.135, Extraído dos Cadernos de Literatura Brasileira: Clarice Lispector, Instituto Moreira Salles, edição especial, números 17 e 18 - Dezembro de 2004.
} 
e a produção de culturas infantis, vão sendo experimentados entre a descrição narrativa, análise fílmica e as articulações teóricas e literárias.

E um segundo momento, focando nas reflexões acerca do cinema como linguagem audiovisual, que permite pensar, criar e construir possibilidades estéticas de uma infância, enquanto tempo a ser inventado e construído na interface das experiências históricas do passado, do presente e do futuro, ou seja, cinemas e infâncias no plural, na diversidade e multiplicidade de pontos de vista. Muitos filmes foram evocados durante a pesquisa, como referências centrais; busquei as relações entre infância, cinema e memória das Ditaduras Militares no Brasil e na América Latina, trazendo reflexões acerca de "A História Oficial" e "Infância Clandestina" (Argentina, 1985 e 2012 respectivamente), "Machuca" (Chile-Espanha, 2004), "A Culpa é do Fidel" (França, 2006), "O Labirinto do Fauno", “A Espinha do Diabo" (Espanha-México, 2006, 2001 respectivamente) e "O ano em que meus pais saíram de férias" (Brasil, 2006). Somando a estes no percurso, busquei a "criança estrangeira" em "Abril Despedaçado" (2001) e "Mutum" (2006), ambos produções brasileiras.

Em um caleidoscópio de imagens e palavras, busquei construir uma metodologia antropofágica e alquímica, tendo como referências fundamentais Walter Benjamim (1985, 1087, 1989), Pier Paolo Pasolini (1990, 2003), Andrei Tarkoviski (2010), Fredric Jameson (1995), Leandro Konder $(1989,1998)$ e Milton de Almeida $(1999,2001)$, saudoso professor-pesquisador do grupo Olho, da Faculdade de Educação da Unicamp.

Também é importante destacar a relação com o território italiano, como uma grande inspiração-referência, considerando as crianças e infâncias no neorrealismo do cinema italiano de Roberto Rosselini à pedagogia da infância e da maravilha de Loris Malaguzzi.

Finalizei o trabalho com um epílogo-experimento criativo, um desvio final para alimentar o pensamento acerca da tese e seu percurso metodológico de pesquisa e criação em educação. Minha intencionalidade foi e continua sendo de provocar, disparar faíscas, inventar poéti- 
cas, instaurar possibilidades de reflexão com criação, proporcionando um espaço de interlocução nas linhas e entrelinhas do texto, buscando deslocamentos possíveis que evidenciem uma estética da infância para a linguagem audiovisual, elegendo o cinema de autor, político, de poesia como referência. Cinema que constrói e descontrói infâncias, a partir de filmes para as crianças, filmes das crianças e com as crianças.

Em especial buscando apresentar e refletir a respeito de um cinema de poesia, como referência, salientando a perspectiva dos cineastas, autores, os grandes poetas do século XX e XXI que fizeram e fazem cinema, como Andrei Tarkovski destacou: "Quando falo de poesia, não penso nela como gênero. A poesia é uma consciência do mundo, uma forma específica de relacionamento com a realidade. Assim, a poesia torna-se uma filosofia que conduz o homem ao longo de toda a sua vida." (2010, p. 18).

Como poetizar a condição social da infância em um mundo marcado pelos horrores das guerras, ditaduras, holocaustos... em que a cultura da violência estrutura a sociedade?

Nesse exercício, a intencionalidade de entrelaçar, ou amalgamar, de alguma forma, em muito disforme à minha trajetória, enquanto pesquisadora, professora, educadora, militante socialista, criança, filha, mãe, mulher, gente no mundo, tudo ao mesmo tempo agora, é assumir a concepção e os riscos inerentes da intensa indissociabilidade entre sujeito e objeto do conhecimento, que busca contribuir para o processo histórico no presente, com as crianças e as culturas infantis que alimentam sonhos e utopias de uma educação emancipatória, transgressora e libertária. .

Numa primeira camada, fragmentos da memória, um rastro para situar por que algumas imagens se sobressaem e se impõem a mim, parto de um lugar preenchido pelo Kairós ${ }^{2}$ benjaminiano de

\footnotetext{
${ }^{2}$ Pertinente destacar de início as inspirações benjaminianas, despertadas também pelas reflexões de Giorgio Agamben em Infância e História: destruição da experiência e origem da história (2005), sobre a cairologia, segundo o autor: "A história, na realidade, não é, como desejaria a ideologia dominante, a sujeição do homem ao tempo linear contínuo, mas a sua liberação deste: o tempo da história é o cairós em que a iniciativa do homem colhe a oportunidade favorável e decide no átimo a própria li-
} 
uma rememoração transformada em roteiro audiovisual, que abre a tese, intitulado: $A$ mãe, em um exercício poético inicial, que é almejado ao longo de toda a tese, de esculpir o tempo.

Uma mulher (1) perseguida pela Ditadura Militar, em meados dos anos 1970 entra em um hospital público de São Paulo, para ali 'dar a luz' a sua filha. Ela está com medo, tem um contato de um médico-amigo da organização clandestina que é militante. Ela está sozinha, seu companheiro foi para a Guerrilha do Araguaia e ninguém sabe o que aconteceu com ele - provavelmente morreu. Ele também não quis saber muito da gravidez da companheira. [...] A porta do quarto se abre, uma enfermeira entra trazendo um bebê no colo pára ao lado da cama e diz: "Aqui Mamãe, sua filhinha, está faminta." A mulher a recebe no braço aperta sobre seu corpo e chora. Chora um choro doído... Um choro da alma. Chora por tudo o que passaram até ali e também por tudo o que virá ${ }^{3}$.

Este argumento-roteiro centrado no nascimento de uma criança, no contexto da ditadura, no dilema da mãe, fechou a minha Dissertação de Mestrado, A poética do cotidiano com Clarice Lispector: emergindo imagens (SILVA, 2008), defendida no Instituto de Artes da Unicamp, no programa de Pós-graduação em Multimeios - Departamento de cinema, em que trabalhei processos criativos, da literatura para o audiovisual, a partir do conceito de transcriação, tendo o livro Laços de Família (LISPECTOR, 1960) como base inspiradora.

Nessa primeira incursão do processo de pesquisa e criação, a questão da mulher foi muito latente, salientando que a escolha pela literatura de Clarice Lispector não foi aleatória, ela me atravessa e é atravessada pelo universo feminino, com seus dilemas, aprisionamentos, condicionamentos e desdobramentos do que significa ser mulher em uma sociedade violentamente marcada pela desigualdade e opressão de gênero.

berdade." (p. 127-128).

${ }^{3}$ Argumento do roteiro A Mãe, ibidem, p. 63. 
Essa consciência perante as desigualdades marcou minhas escolhas em relação à linguagem cinematográfica, que me permitiu provocar reflexões na tríade que proponho para a discussão estética: a arte, a ciência (as Ciências Humanas) e a política. Falar de cinema de autor, de poéticas cinematográficas, de cinema político, engajado, pode soar ultrapassado em tempos de crise de utopias e muros derrubados; porém, com a emergência do fascismo, creio que alguns discursos cinematográficos revigoram-se em sua atualidade e relevância, sobretudo a partir dos óculos e das escolhas de quem os vê.

Ter olhos para ver, como nos incitou José Saramago, na epigrafe de seu belíssimo Ensaio sobre a Cegueira (1998): "Se podes olhar, vê. Se podes ver, repara”; para além de enxergar perdemos a capacidade de ver, reparar e se indignar perante os horrores do mundo que recaem sobre as crianças, suas infâncias.

\section{Segundo movimento}

\section{Da estética da infância à \#noinono.org ${ }^{4}$ : pedagogia da maravilha, femi- nicidio e a luta das mulheres}

Durante o ano de 2012, pude ter na minha formação acadêmi$\mathrm{ca}^{5}$ e de vida uma experiência profunda com a Itália, em especial com a Cinemateca de Bologna, seguindo 'os rastros' do Professor Milton de Almeida, pesquisando no Fondo Pier Paolo Pasolini, onde encontrei ao acaso com Cecilia Mangini, esquecida pela própria cinematografia italiana, que somente nos últimos dez anos vem sendo retomada e aclamada como a maior documentarista do pós-guerra italiano, realizadora do primeiro documentário feminista na Itália "Essere Donne"6.

\footnotetext{
${ }^{4}$ Trata-se de uma Organização Não Governamental italiana, que vem deste 2012 atuando no combate à violência de gênero, com foco na sensibilização com homens. $<\underline{\text { http://www.noino.org/> }}$

${ }^{5}$ Participei do PDSE - CAPES Doutorado Sanduíche junto à Università degli studi di Milano Biccoca, sob orientação do antropólogo Roberto Maliguetti.

${ }^{6}$ Em 2010, Cecilia Mangini foi homenageada pelo Archivio del movimento operaio e democratico., que produziu o primeiro filme feminista na Itália, Essere Donne em $<\underline{\text { http://www.aamod.it/archivio-file-e-notizie-recenti/cecilia-mangini }>}$
} 
Cecilia Mangini (Bari, 1927) entra na cena cinematográfica italiana colaborando com Pasolini, que se torna uma grande referência nos documentários que realiza nos anos 1960: Stendali (1960) e La canta delle Marane (1961). O primeiro, realizado em Cinema del Reale, realizada Salento, Puglia, no sul da Itália, que retrata de forma poética um fúnebre ritual das mulheres chorando seus mortos, e o segundo, inspirado no romance de Pasolini, Ragazzi di Vita (1955), retrata meninos brincando no Rio Tevere, em Roma, nos anos 1960. Ambos são documentários curtos e poéticos, com temáticas populares, do cotidiano do povo, referenciando explicitamente na forma-conteúdo o diálogo e a inspiração pasoliniana.

Cecilia Mangini também fez parte da escola antropológica, o gruppo demartiniano, referência a Ernesto de Martino (Nápoles, 1908 - Roma, 1965), antropólogo, etnólogo, militante comunista, um grande estudioso da magia e religião no sul da Itália, que nos anos 1950 e 1960 realizou diversos documentários antropológicos sobre a Itália meridional $^{7}$.

Segundo Cecilia Mangini, em entrevista na Festa di em julho de 2013, na pequena cidade de Spechia (Salento, Puglia, na Itália) o cinema nasce do documentário, do registro do cotidiano, remetendo aos irmãos Lumière e à célebre projeção da chegada do trem na estação; e atualmente, indica a documentarista, cem anos depois, o cinema retoma cada vez mais suas raízes estéticas de opção pelo real, pela poética da realidade.

Muito recentemente, Cecilia Mangini, atualmente com 92 anos, teve seu clássico Essere Donne $e^{8}$ restaurado pela Cineteca di Bologna, e um amplo debate na mídia italiana referente à pertinência e atualidade de seu documentário. Do sucesso no exterior ao boicote italiano na época de seu lançamento, às questões que ele coloca no pre-

\footnotetext{
${ }^{7}$ Vale ressaltar para compreender o contexto destas questões o clássico texto A questão meridional (1926), presente na coletânea Escritos Políticos, de Antonio Gramsci, 2004.

${ }^{8}$ A cópia restaurada pelo Archivio Audiovisivo del Movimento Operaio e Democra-

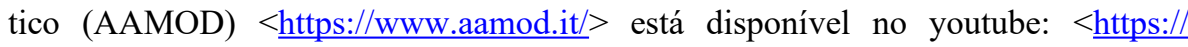
www.youtube.com/watch?v=mk25pEfwcX4 > Acesso em: 2 fev. 2020.
} 
sente, do quanto nós, mulheres, estamos ainda enredadas na complexidade da questão do que é ser mulher? Do quanto os processos de opressão e exploração condicionam e limitam a existência.

Minha experiência italiana também foi uma história de dor e de horror, que marcou a presente pesquisadora, artista, arteira, filha de operários que jamais tinha saído do país, fascinada em meio ao seu doutorado, com a oportunidade única, de passar um ano em um pequeno país europeu, distante e belo, referência histórica no mundo ocidental pelo Renascimento que marca a história das artes e da beleza, que há décadas vem encantando por sua Pedagogia da infância e da maravilha, criada no pós-guerra, em meio à dor e ao horror, como nostalgia do futuro ${ }^{9}$.

Deparei-me com um belo país, pequeno em extensão territorial, porém, profundo em reexistêncas, pois se trata de um território repleto de contradições; entre muitas, a pior e mais perversa para a pesquisadora artista arteira foram os dados alarmantes de violência contra as mulheres e o encontro com o termo, a história e o movimento de luta contra o feminicídio, a partir do livro Femminicidio. Dalla denuncia sociale al riconoscimento giuridico internazionale ${ }^{10}$ (2008), de Barbara Spinelli, que encontrei na Biblioteca delle donne, de Bologna.

Durante todo o ano de 2012, em meu estágio de doutorado sanduíche, realizado na Università Milano Bicocca, em Milão, na Itália, pude acompanhar pela mídia casos de feminicídio, na Lombardia.

\footnotetext{
${ }^{9}$ Nostalgia do futuro remete-se a Loris Malaguzzi e à pedagogia da infância e da maravilha, criada por ele e demais educadores italianos no pós- guerra em Reggio Emilia, no centro norte da Itália. (FARIA E SILVA, 2015)

${ }^{10}$ Barbara Spinelli é uma jovem advogada e parlamentar italiana, ativista feminista, foi com este livro pioneira no contexto europeu na divulgação do termo; segundo a autora, feminicídio é uma categoria de analise sociocriminológica de discriminação e violência contra as mulheres por fazerem parte do gênero feminino. Em seu livro, relata os alarmantes casos de assassinato de mulheres na Cidade de Juarez, na fronteira do México com os Estados Unidos, que vem se destacando pelas denúncias e lutas contra o feminícídio, tornando-se um marco mundial. No Brasil, foi aprovada, em 2015, pela presidenta Dilma Roussef, a lei 13.104, que altera o Código Penal para prever o feminicídio como um tipo de homicídio qualificado e incluí-lo no rol dos crimes hediondos.
} 
Tentava me instalar e acompanhar o trabalho educativo em um Asilo Nido, que me acolheu para o estágio; porém, foi na região de Bolonha - histórico epicentro criativo da esquerda, que encontrei um movimento feminista articulado nos processos de denúncia, campanhas educativas em um amplo e criativo movimento de resistência. “Diventare uomini senza violenza”, com este slogan, lançado em 2012, deparei-me com um dado concreto muitas vezes negligenciado de apontar quem são os autores da violência contra as mulheres, que homens e mulheres sem violência são um desafio da sociedade, que exige investir em processos formativos.

Também nesse mesmo fatídico ano, pude conhecer o trabalho de educadoras de creches da rede municipal de Bolonha; nas creches San Donato e Viganò, por ocasião do 25 de novembro, Dia Internacional Contra a Violência Contra as Mulheres. Todo dia 25 de novembro, as famílias são convidadas a passar o dia na creche junto com as crianças. Durante o acolhimento, é distribuído material informativo da "Casa delle donne per non subire violenza" (Casa das Mulheres para não sofrerem violência), e é criado um espaço com poemas acerca do tema. Na parte da manhã, é proposta uma performance artistica, elaborada pelas professoras, com uma oficina envolvendo as crianças, as mães e os pais. A performance, repleta de elementos simbólicos, proporciona alternativas relacionadas ao tema do dia, marcadas por uma forte partilha de pensamentos e emoções.

Retornei ao Brasil no início de 2013, fortemente marcada por essa experência; em seguida, iniciei um trabalho como docente na Universidade Federal de Florianópolis, na área de estágio nos anos iniciais do Ensino Fundamental; finalizei a tese, mas a viagem continuava ressoando no meu percurso formativo.

Cabe destacar que essa ressonância se acentuou a partir do encontro com o trabalho de Albertina Carri, jovem cineasta argentina, que esteve em 2013 na Semana do Curso de Cinema da UFSC, apresentando seu longa La Rabia (2018), e com o curta documentário 
Quem matou Eloà ${ }^{11}$ (2015), de Livia Perez. Quem matou Eloà, os pais desaparecidos da jovem cineasta Albertina Carri na ditadura militar argentina, drama revisitado no filme La Rabia, mas exposto no curta documentário Los Rubios ${ }^{12}$ (Argentina, 2003), apresentam homens que 'amam-odeiam' as mulheres, estados ditatoriais comandados por generais-homens, em uma sociedade que é conivente com a violência, ou responsável por uma cultura da violência estrutural? (hooks, 2018).

No processo de pesquisa, na escrita da tese, um dos resultados mais significativos foi que todo esquecimento é revestido da emergência da lembrança, de rememorar, a infância rememorada no cinema de jovens cineastas eram memórias de crianças que sofreram nas ditaduras latino-americanas. Nessa direção, retornei ao roteiro, a mãe, já trabalhada no Mestrado, o lugar da maternidade, para localizar que não tem infância sem a discussão das mulheres, das condições de vida e existência do que é ser mulher, mães que na base do horror, medo, ge nocídio de mulheres sustentam a sociedade capitalista patriarcal (FEDERICI, 2019).

\section{Terceiro movimento}

\section{No princípio não era o verbo, sim a ação: \#aprimaveraestáchegando}

Dediquei a tese à minha mãe e às mulheres guerreiras que se movimentam, não aceitam as amarras que as prendem e lutam e sonham. E trouxe na epígrafe Rosa Luxemburgo, um fragmento de uma carta escrita na prisão, alguns dias antes do seu assassinato pelos nazistas, aos 47 anos, em 15 de janeiro de 1919.

${ }^{11}$ Em 2009, Lindemberg Alves, de 22 anos, invadiu o apartamento da ex-namorada, Eloá Pimentel, de 15 anos, armado, mantendo-a refém por cinco dias. O crime foi amplamente transmitido pelos canais de TV. O filme traz uma análise crítica sobre a espetacularização da violência e a abordagem da mídia televisiva nos casos de violência contra a mulher, revelando um dos motivos pelo qual o Brasil é o quinto num ranking de países que mais matam mulheres.

${ }^{12}$ Los Rubios é um documentário / drama argentino e americano de 2003, dirigido por Albertina Carri e escrito por Carri e Alan Pauls. O filme premiado documenta a busca da diretora Albertina Carri enquanto ela investiga o que aconteceu com sua família durante a "Guerra Suja" da Argentina. 
No meio das trevas, sorrio à vida, como se conhecesse a fórmula mágica que transforma o mal e a tristeza em claridade e em felicidade. Então, procuro uma razão para esta alegria, não a acho e não posso deixar de rir de mim mesma. Creio que a própria vida é o único segredo ${ }^{13}$.

Ingressei como professora de Educação Infantil na rede municipal de Florianópolis, em 2015, após uma breve experiência na rede municipal de Campinas, tendo mais anos de formação, pesquisa e docência no ensino superior. Porém, imbuída com o desejo e a possibilidade de vivenciar uma prática docente feminista, que vem se tornando nos últimos anos uma perspectiva teórico-metodológica inerente da minha condição docente em qualquer nível de ensino ou prática edu cativa em que atue. Tenho na dimensão da desconstrução das relações opressivas de gênero um dos maiores desafios ao exercer uma pedagogia emancipatória, assim como mantive o vínculo como pesquisadora no âmbito do projeto de pesquisa e cooperação científica internacional "Instituições educativas para crianças de zero a dez anos: interlocução de pesquisa entre Brasil e Itália", que envolve universidades brasileiras e a Università degli Studi di Milano-Bicocca, da Itália.

Cabe destacar que na história da Pedagogia houve uma descoberta tardia das relações de gênero que permeiam os processos educativos das crianças, bem como os processos de formação de professores e professoras (ROSEMBERG, 1996; CERISARA, 1996) que alinhem esta interlocução das categorias infância e gênero (VIANA; FINCO;

\footnotetext{
${ }^{13}$ Reencontrei esta epígrafe no livro Rosa Vermelha uma biografia em quadrinhos de Rosa Luxemburgo (2017) de Kate Evans, na nota 173 há uma pequena diferença, que creio ser da tradução, mas a continuidade me inspira "[...]; a profunda escuridão da noite é bela e macia como o veludo, desde que a olhemos da maneira correta; e no esmigalhar da areia molhada sob os passos lentos e pesados das sentinelas uma bela cançãozinha de vida se faz ouvir - desde que se saiba ouvi-la. Nestes momentos penso em você e gostaria muito de comunicar a você essa chave mágica, para que sempre e em todas as situações tenha consciência do que é belo e alegre, para que também viva numa euforia de felicidade, como se estivesse caminhando por um prado multicolorido. Luxemburg, Letters, p. 455.
} 
2009). Assim como a pedagogia da infância ou a Educação Infantil, definida por Rocha (1999) como uma subárea na educação que vem se consolidando a partir da consolidação e expansão pós LDB, da Educação Infantil como primeira etapa da Educação Básica em creches e pré-escolas, em um movimento de crítica e criação multidisciplinar, com foco nos processos educativos de apropriação e produção das culturas infantis.

É inevitável ressaltar o silenciamento da área educacional com a questão feminina que emerge com os movimentos sociais, apontando para os desafios e contradições contemporâneos de uma pedagogia das diferenças, comprometida com a emancipação humana. Consciente das desigualdades históricas, busco na minha práxis docente identificar a manutenção dos binarismos e das relações de poder desiguais, tendo a creche como locus privilegiado de uma pedagogia descolonizadora (FINCO; FARIA; GOBBI, 2015).

Nesta direção, as chaves do processo de construção de uma pedagogia feminista, permeada por poéticas da resistência, comprometida com a emancipação humana, está no movimento criativo de articular pedagogia, formação e a experiência estética, com um percurso formativo que envolve os estudos de gênero, perspectivas feministas e a educação, destacando os processos criativos que suscitam a tomada de consciência de gênero das mulheres nos seus processos formativos (SILVA, 2008). E também apontando as complexidades que permeiam os processos de socialização que condicionam e buscam determinar os papéis sociais das mulheres e dos homens, porém com ênfase naquelas que, majoritariamente, são responsáveis históricas pela educação e cuidados na infância.

Nessa perspectiva, tive a experiência de atuar como decente pesquisadora em jornadas de luta contra a violência no contexto de creche, em 2016 e 2017, em duas creches públicas da rede municipal de Florianópolis, inspirada pelas educadoras de Bologna que vêm realizando atividades relacionadas ao 25 de novembro, declarado Dia Internacional da Não - Violência contra a Mulher, no Primeiro Encontro Feminista da América Latina e Caribe realizado na cidade de Bogotá 
em 1981, como justa homenagem a "Las Mariposas", codinome utilizado em atividades clandestinas pelas irmãs Mirabal, heroínas da República Dominicana brutalmente assassinadas em 25 de novembro de 1960. Minerva, Pátria e Maria Tereza ousaram se opor à ditadura de Rafael Leônidas Trujillo, uma das mais violentas da América Latina.

A partir da minha experiência com o 25 de novembro, viajando pela Itália e me reportando diretamente à história latino-americana, uma vez que a data tem em sua origem uma homenagem póstuma e simbólica às irmãs assassinadas na República Dominicana - Las mariposas, e tendo como símbolo poético os sapatos vermelhos - remetendo às mulheres da Cidade Juarez no México, com a instalação dos Zapatos Rojos, de Elina Chauvet, 'viralizando' em praças ao redor do mundo, associei no meu intuito de fazer algo no Brasil, no meu contexto da educação infantil, permeado pelas narrativas clássicas da his tória dos Sapatinhos Vermelhos, buscando criar possibilidades de uma práxis pedagógica feminista, transgressora de reinterpretação narrativa junto com as crianças.

O conto Sapatinhos Vermelhos, de autoria de Hans Cristhian Andersen, publicado em meados do século XIX, relata a trágica história de uma pobre órfã que perde seus pés por conta da sua cobiça por reluzentes sapatos vermelhos de baile. Na minha interpretação, a narrativa é repleta de simbolismos misóginos, de controle do corpo e moralismo religioso, reflexo da época e contexto de sua criação e/ou vinculação. Segundo Katia Candon (2014), Hans Christian Andersen é considerado o primeiro escritor moderno de contos de fadas, porque utilizou tradição de contos populares - narrativas ligadas ao povo nórdico, que foram adaptadas por ele - mas, em sua maioria, criou textos inéditos, que brotavam de sua própria experiência, marcada pela miséria na infância e adolescência.

Porém, na minha leitura, trata-se de uma narrativa perversa de horror, que resiste e insiste nas marcas simbólicas pelo mundo de sapatos vermelhos que apontam a cada ano o crescente número de mulheres desaparecidas, assassinadas por serem mulheres. 
Nessa perspectiva, em interlocução com a gestão e colegas professoras no interior da creche e fora dela no contexto acadêmico de pesquisa, iniciei a elaboração de um projeto intitulado: NIUNAMENOS ${ }^{14}$ : relações de gênero, poéticas da resistência e políticas de desconstrução das violências, que tem como intencionalidade pedagógica promover ações educativas através de intervenções artísticas - em diversas linguagens, mas, sobretudo, tendo como eixo central a literatura dos contos de fadas (que se configuram como clássicos infantis mundiais e podem ser conectados com uma perspectiva de feminismo transnacional), como chave para a problematização das violên cias que perpassam as relações de gênero, buscando desconstruir estereótipos e normatizações de comportamentos entre mulheres/meninas e homens/meninos.

As ações perpassam diversas e importantes frentes da Educação Básica: da creche à universidade - com foco nas crianças/adolescentes a estudantes do curso de Pedagogia, visando promover uma práxis na área de formação de professoras/es a partir de contação de histórias, dramatizações, leituras literárias e exibições de filmes.

A escolha dessa temática foi justificada entre meus pares por vivenciarmos em nosso cotidiano expressões constantes de violências de toda ordem: tanto no espaço externo como no interno da creche, sobretudo nas relações interpessoais, e buscou inserir um projeto piloto integrado ao nosso campo de atuação político pedagógico com ações concretas de sensibilização à temática e educação preventiva no combate às violências de gêneros. Cabe salientar que também responde especialmente na emergência do aumento da violência contra as mulheres e crianças, que observamos com frequência em nossos cotidianos na creche.

Ao trazer esta temática para meu trabalho docente nos coletivos infantis em que estava atuando, busquei, junto à comunidade, trazer uma perspectiva de "descolonização global", que visualizo como

\footnotetext{
${ }^{14}$ NIUNAMENOS faz referência ao movimento de luta na argentina contra o feminicídio brutal da Argentina em que Lucía Pérez, com 16 anos, que em outubro de 2016 mobilizou manifestações de mulheres em diferentes países pelo mundo.
} 
desafio político a uma pedagogia da Educação Infantil transgressora. Instigava a uma reflexão coletiva em como construir um olhar feminista transnacional para os direitos das crianças, com a intencionalidade libertadora manifesta de educar crianças feministas (ADICHIE, 2017), trazendo, sobretudo, a creche e a pré-escola como locus histórico de luta feminista, visando a outras práticas educativas para as crianças pequenas, bem como fomentando pesquisas e novas teorias, em busca de práxis emancipatória e descolonizadora, através de poéticas da resistência para a formação docente.

Cabe destacar que no caso brasileiro, a história da luta feminista por creche, conforme afirma Teles (1999), também foi permeada por uma educação para transgressão e subversão de ranços assistencialistas, com um movimento das mulheres de periferia repleto de processos criativos, como a utilização de paródias às cantigas de roda: " $E u$ fui à Prefeitura, buscar creche, não achei, achei tanta promessa, quase que eu desanimei. Olhe, seu prefeito, eu sou uma criança, mas sei meus direitos. O meu pai trabalha duro, o dinheiro nunca dá, eu preciso de uma creche para mamãe ir trabalhar" (paródia da cantiga de roda "Eu fui no Itororó") (p. 105). Neste fragmento, pode-se refletir no quanto a problematização da divisão sexual do trabalho, das transformações das relações sociais fazem parte da educação das crianças em sua luta por direitos.

Nesse sentido, tenho buscado uma docência comprometida com uma formação permanente, que visa construir interlocuções entre as Ciências Humanas e Sociais. Os movimentos sociais e a Arte como possibilidades para contribuir com o grande desafio de construir coletivamente transgressoras poéticas da resistência na formação docente para atuar na educação da infância. Buscando conteúdos em diversas linguagens que articulam a revisão de conceitos que foram construídos historicamente, mas perversamente cristalizados e invisibilizados, e que precisam ser repensados e revisitados, abordando a indissociabilidade entre a educação e o cuidado; enfatizando práticas educativas para emancipação das relações de gênero; com processos de construção de identidade docente politizados, considerando a identidade de 
gênero na formação docente; a relação com a família, seus arranjos e suas diversidades, e as linguagens infantis e as culturas infantis, a fim de coletivamente dar um basta junt@s contra as violências de gênero.

\section{Referências}

ADICHIE, Chimamanda N. Para educar crianças feministas: um manifesto. São Paulo: Cia das Letras, 2017.

AGAMBEN, Giorgio. Infância e história: destruição da experiência e origem da história. Belo Horizonte: UFMG, 2005.

ALMEIDA, Milton J. Imagens e Sons: a nova cultura oral. São Paulo: Cortez, 2001.

. Cinema Arte da Memória. Campinas: Autores Associados, 1999.

BECCHI, Egle. Ser menina ontem e hoje: notas para uma pré-história do feminino. Pro-Posições. Dossiê: Educação Infantil e gênero, v. 14, n. 3, (42), p. 41-52, 2003.

BELOTTI, Elena. Educar para a submissão. Petrópolis: Vozes, 1975. CANDON, Katia. Minimaginário de Anderson. São Paulo: Companhia das Letrinhas, 2014.

CERISARA, Ana Beatriz. A construção da identidade dos profissionais e educação infantil: entre o feminino e o profissional. Universidade de São Paulo, 1996- Tese (Doutorado em Educação) - USP, São Paulo,1996.

EVANS, Kate. Rosa Vermelha: uma biografia em quadrinhos de Rosa Luxemburgo. São Paulo: Editora WMF Martins Fontes, 2017.

FARIA, Ana Lúcia G de.; SILVA, Adriana A. Por uma nova cultura da infância: Loris Malaguzzi. Revista Educação Especial, v. X, p. 98-111, 2013. 
FEDERICI, Silvia. O calibã e a bruxa. Mulheres, corpo e acumulação primitiva. (tradução coletivo Sycoraux), São Paulo: Editora Elefante, 2017.

. Mulheres e caça as bruxas: da Idade Média aos dias atuais. São Paulo: Boitempo, 2019.

FINCO, Daniela; GOBBI, Marcia A.; FARIA, Ana Lúcia Goulart de Creche e Feminismo: desafios atuais para uma educação descolonizadora. Campinas, SP: Edições Leitura Crítica; Associação de Leitura do Brasil - ALB; São Paulo: Fundação Carlos Chagas - FCC, 2015.

hooks, bell. Ensinando a transgredir: a educação como prática da liberdade. São Paulo: Editora WMF Martins Fontes, 2013.

O feminismo é para todo mundo: politicas arrebatadoras. Rio de Janeiro: Rosa dos Tempos, 2018.

GRAMSCI, Antonio. Escritos Políticos- 1921-1926. (edição Carlos Nelson Coutinho) Rio de Janeiro: Editora Civilização Brasileira, 2004. v. 2 .

KONDER, Leandro. Fourier, o socialismo do prazer. Rio de Janeiro: Civilização Brasileira, 1998.

Walter Benjamim: o marxismo da melancolia. Rio de Janeiro: Campus, 1989.

LISPECTOR, Clarice. Laços de Família. Rio de Janeiro: Ed. Rocco, 1960.

A descoberta do mundo. Rio de Janeiro: Ed. Rocco, 1984.

MANTOVANI, Susanna; PERANI, Rita M. Uma profissão a ser inventada: o educador da primeira infância. Campinas. Revista Proposições. v. 10, n. 128 mar. 1999.

PASOLINI, P. P. Genariello: a linguagem pedagógica das coisas. In: LAHUD, M. (org.) Os jovens infelizes: antologia de ensaios corsários. São Paulo: Editora Brasiliense, 1990. p. 125-136. 
. Lettere luterane. Il progresso come false progresso. Torino:

Einaudi Ed., 2003.

PHELPS, Ethel. J. (Org.) Chapeuzinho Esfarrapado e outros contos feministas do folclore mundial. São Paulo: Seguinte, 2016.

ROCHA, Eloisa. C. A pesquisa em educação infantil no Brasil: trajetória recente e perspectivas de consolidação de uma pedagogia- Unicamp, 1999. (Tese de Doutorado). UNICAMP, Campinas, 1999.

ROSEMBERG, Fúlvia. Teorias de gênero e subordinação de idade: um ensaio. Pro-Posições, v. 7, n. 3, p. 17-23, nov., 1996.

SARAMAGO, José. Ensaio sobre a cegueira. São Paulo: Cia das Letras, 1998.

SILVA, Adriana A. A Poética do Cotidiano com Clarice Lispector: emergindo imagens. Dissertação (Mestrado em Multimeios: Cinema e Vídeo) - Universidade Estadual de Campinas (Instituto de Artes, UNICAMP), Campinas, 2008.

. A Estética da Infância no cinema: poéticas e culturas infantis. Universidade de Campinas, 2014- Tese (Doutorado em Educação). Faculdade de Educação, Unicamp, Campinas, 2014.

SPINELLI, Barbara. Femminicidio. Dalla denuncia sociale al riconoscimento giuridico Internazionale. Franco Angeli, 2008.

TARKOVSKI, Andrei. Esculpir o Tempo. São Paulo: Martins Fontes, 2010.

TELES, Maria Amélia. Breve história do feminismo no Brasil. São Paulo: Brasiliense, 1999.

VIANNA, Claudia; FINCO, Daniela. Meninas e meninos na Educação Infantil: uma questão de gênero e poder. Campinas, SP. Cadernos Pagu [online]. n. 33, p.265-283, 2009. 
